\title{
Research on Characteristics and Formation Mechanism of Landslide Disaster in Red Soil Hilly Region of South China
}

\author{
Qinghua Gong \\ Guangzhou Institute of Geochemistry, Chinese Academy of Sciences, Guangzhou 510640, China \\ Guangzhou Institute of Geography, Guangzhou 510070, Guangdong, China \\ University of Chinese Academy of Sciences, Beijing 100049, China \\ Guangqing Huang \\ Guangzhou Institute of Geochemistry, Chinese Academy of Sciences, Guangzhou 510640, China \\ Junxiang Zhang \\ Tourism College, Huangshan University, Huangshan245021, China \\ Received 28 June 2013 \\ Accepted 7 July 2013
}

\begin{abstract}
The mechanism of landslide hazard in weathering crust of granites in south china was chosen as our research object. Landslides, as a common geo-hazard, can result in huge economic losses and enormous casualties in mountainous regions of the world. Therefore, the mechanism of landslide hazard has become a topic of major interest for both geoscientists and engineering professionals. Take the landslides mechanism as the key problem. Firstly, we will analyze the regularity of its regional differentiation in those area based on the field investigations and the available data in the area according to the features of this kind of landslide. Secondly, we will reveal the growth characteristics and disaster mechanism of landslide by study the relationship between the characteristics of intensity and frequency of landslide and meteorological factors, hydrologic geology, geologic factors, landform and human factors and so on. Finally, based on these result, the regional landslide prediction model was obtained by quantification approach. The final goal is to reduce the landslides risk as low as possible. Our subject will provide scientific basis for risk precaution and disaster emergency response.
\end{abstract}

key words : South China; the red soil hilly region; landslide; mechanism

\author{
华南红壤丘陵区滑坡灾害特点及致灾因素分析 \\ 宫清华 ${ }^{1,2,4}$, 黄光庆 ${ }^{1,2}$, 张俊香 $^{3}$ \\ 1. 广州地理研究所, 广州 510070 \\ 2.中科院广州地球化学研究所, 广州 510640 \\ 3. 黄山学院旅游学院, 黄山 24502 \\ 4.中国科学院大学, 北京 100049
}

\begin{abstract}
摘要: 本文针对华南沿海风化壳滑坡的特点, 以近年华南沿海地区的千余处滑坡灾害点的空间分布和地质 环境特征等资料为基础, 研究花岗岩风化壳滑坡的孕灾环境和灾害强度、灾害规模、范围等空间分布特征 地域分异规律; 解析华南沿海花岗岩风化壳滑坡灾害的发生规律和形成机理; 分析滑坡灾害强度和频度与 地质、地貌、气象、水文、生态人文的关系。本研究对滑坡灾害机理研究有重要的科学意义, 对华南沿海 未来在滑坡灾害风险防范的对策和灾害应急预案的制定具有极重要的参考依据。
\end{abstract}

关键词：华南，红壤丘陵区，滑坡，形成机理

\section{1.引言}

华南沿海地区以花岗岩风化壳分布最广，该地区 在雨季，地下水沿不透水风化层面流动使得滑坡灾害 频发, 华南地区山地处在强烈的季风作用交互带上, 在全球气候变化和不断加剧的人类活动影响下, 山地 系统脆弱性更为明显。特别是华南山地区域目前正处 于快速城市化和城乡统筹发展这一整体社会发展背景 下, 华南红壤丘陵区正在发生巨大的变化, 也使得山
区地质环境面临着巨大的威胁, 而滑坡灾害时威胁山 区人居环境的突出生态问题。据统计，连降雨偏少三 成的 2010 年广东省发生较大规模的突发性地质灾害 也达到 238 宗，其中，滑坡 103 宗，华南山区滑坡灾 害防治任务刻不容缓, 但灾害防治领域的一系列科学 问题还有待突破，尤其是滑坡灾害的诱发机理问题一 直是世界上公认的难题 ${ }^{11]}, 21$ 世纪初美国地质调查局 的滑坡灾害减灾战略规划, 将滑坡过程和诱发机理研 究列为首要的任务, 这不仅因为滑坡、泥石流形成机 
理和诱发机理研究是至今没有突破的难题, 更重要的 是它成为制约地质灾害预测预警和防灾、减灾研究的 瓶颈问题。因此, 长期以来, 国内外许多地学专家、 学者都将其作为攻克目标, 经过多年的发展, 对滑坡 发育机理的研究取得了一些探索性的成果。但对于华 南花岗岩风化壳地区的滑坡, 在很多方面的问题尚待 解决。本文试图通过解析华南红壤丘陵区滑坡灾害的 形成机理, 探索滑坡灾害发育的本质规律, 并对华南 山区未来的滑坡灾害发育趋势做出基本的判断。这对 系统地发展有中国地理特色的地球系统科学具有特殊 的科学价值和重要科学意义, 并对提高我国在国际地 球系统科学领域的科技影响力和引领作用具有更重大 的意义。

\section{2. 华南红壤丘陵区地质地貌特征 \\ 2.1 研究区概况}

华南地区的滑坡灾害与地质环境, 尤其与风化壳 发育深厚的地质环境有着密切的关系 ${ }^{[2]}$ 。华南地区的 滑坡几乎大部分都分布于各种岩类的风化壳发育地 带, 尤其在花岗岩类风化壳区域的案例相对较多。花 岗岩风化壳又是华南沿海分布最广的风化壳类型。广 东省梅州地区是属于典型的花岗岩地区, 根据前期工 作的调查表明, 该区域花岗岩风化壳厚度较大, 约有 16-19.5m, 因此, 本项研究选择梅州市域作为红壤丘 陵区滑坡灾害发生规律和成灾机理研究的范围。梅州 市位于广东省东北部, 地理坐标东经 $115^{\circ} 18^{\prime}-116^{\circ} 56^{\prime}$, 北纬 $23^{\circ} 23^{\prime}-24^{\circ} 56^{\prime}$ 。东南与潮州市、揭阳市、汕尾市 接壤, 东北与福建省南靖、永定、武平毗邻, 西部与 河源市、江西省寻乌相连。面积 $15876.05 \mathrm{~km}^{2}$ 。梅州 市的地貌格局和灾害点分布情况如图 1。

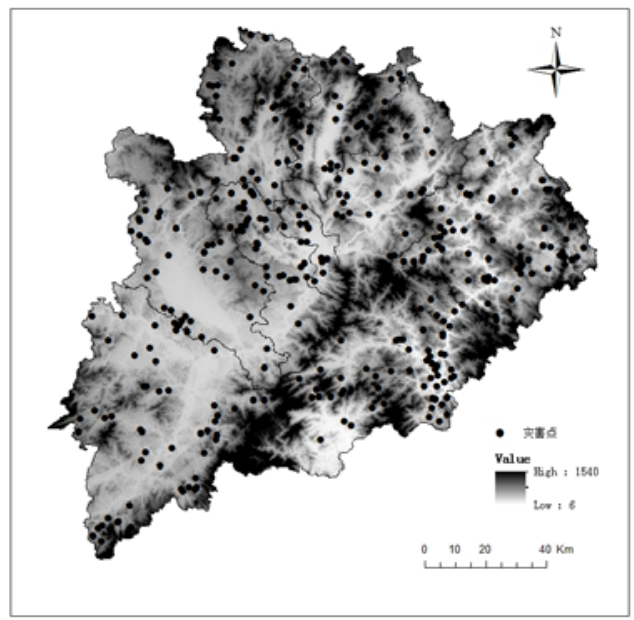

图 1 灾害点与高程分布图

表 1 红壤型风化带物理力学性质表 (据何珊儒, 2005)

\begin{tabular}{|c|c|c|c|c|c|c|c|}
\hline 风化带 & $\begin{array}{l}\text { 密度 } \\
\left(\mathrm{g} / \mathrm{cm}^{3}\right)\end{array}$ & $\begin{array}{l}\text { 干容重 } \\
\left(\mathrm{g} / \mathrm{cm}^{3}\right)\end{array}$ & $\begin{array}{l}\text { 吸水率 } \\
(\%)\end{array}$ & $\begin{array}{l}\text { 孔隙率 } \\
(\%)\end{array}$ & $\begin{array}{l}\text { 饱和吸水率 } \\
(\%)\end{array}$ & $\begin{array}{l}\text { 极限抗压强度 } \\
(\mathrm{MPa})\end{array}$ & $\begin{array}{l}\text { 极限抗拉强 } \\
\text { 度 ( } \mathrm{MPa})\end{array}$ \\
\hline 强风化带 & $2.62-2.64$ & $2.40-2.50$ & $2.50-2.55$ & $5.30-6.10$ & $2.51-2.83$ & $3.50-9.30$ & $2.40-3.27$ \\
\hline 中风化带 & $2.63-2.652$ & $2.38-2.56$ & $0.90-3.92$ & $2.80-9.93$ & $1.23-4.69$ & $38.40-65.70$ & $1.44-54.31$ \\
\hline 微风化带 & $2.62-2.67$ & $2.55-2.63$ & $0.40-0.45$ & $1.56-2.30$ & $0.30-0.45$ & $65.50-138.20$ & $5.86-12.12$ \\
\hline 新鲜基岩 & $2.64-2.67$ & $2.58-2.64$ & $0.38-0.42$ & $1.18-1.50$ & $0.35-0.43$ & $143.76-238.12$ & $5.63-13.46$ \\
\hline
\end{tabular}

\section{3 风化壳的地质力学特性}

\section{2 红壤丘陵区风化壳剖面划分}

华南地区地处亚热带, 气候热湿, 干湿季节明显, 在地势低平和坡度和缓的丘陵低山区, 形成了巨厚的 花岗岩红色风化壳 ${ }^{[2]}$ 。华南沿海约有 $70 \%$ 的面积为中生 代花岗岩和火山岩所占, 其余为新生代玄武岩、各时 代的沉积岩和少量的变质岩以及松散的第四系。基岩 的表层在高温 (年平均气温 $21-28^{\circ} \mathrm{C}$ ) 和潮湿 (年降雨 量 000-2000mm, 年相对湿度 75-85\%) 的气候条件下, 分解和淋溶作用极强, 发育为富铝风化壳, 相对富集 了铁、铝、钦等活性较小的元素, 而以红色为特征, 红壤型风化壳, 是华南沿海分布最广的第四系类型。 不同岩性其风化壳的厚度差异很大, 砂页岩的风化壳 一般仅几米厚, 石灰岩风化壳的厚度一般小于 $10 \mathrm{~m}$, 花岗岩由于节理特别发育 (包括水平和垂直节理), 所 以比其他岩石风化作用更为深入, 因而形成了较深厚 的风化壳。根据化学风化程度的不同, 把花岗岩风化 壳自上而下分为四层：全风化层、强风化层、弱风化 层和微风化层 ${ }^{\mathbf{I} \mathbf{I}}$, 最厚的可达 50-60m。细粒花岗岩为 20-30m (广东梅州), 而粗粒或斑状花岗岩风化壳的厚 度可达 70-80m (广东陆丰), 这也为滑坡的发育提供了 物质基础 ${ }^{[4,5]}$ 。

随着风化程度的加深, 风化层的物理力学性质也 随之变化, 风化岩石的比重、干容重等指标多呈降低 的趋势, 而其孔隙率和吸水率等指标多呈增加的趋势; 而随着风化程度的加深, 岩石强度呈逐渐下降的趋势。 ${ }^{[6,7]}$ 花岗岩风化壳的各物理力学特征如表 1 。

斜坡整体的稳定状态主要取决于斜坡内部的构造 力学特性和物质组成, 从上表可以看出, 红壤型风化 壳中吸水性和孔隙度随着风化程度的增加而减少, 到 基岩为不透水层, 而风化土是一种随着含水量而表现 出显著软化的特殊性土, 在表层风化壳软化, 基岩不 透水, 表层土体松散软弱, 基岩完整坚硬的垂直分布 格局下, 若有含水性质或力学荷载发生变化时, 斜坡 内部平衡极易收到破坏，进而形成浅层滑坡。

\section{4 红壤丘陵区的地貌形态特征}

在华南沿海, 发育厚层风化壳的花岗岩山丘, 形 态多圆浑, 一般坡度多在 30 度左右。研究区梅州市位 于粤东低山-丘陵区的东部, 以山地丘陵为主, 山谷相 间的地貌格局, 地势起伏较大。海拔 $100 \mathrm{~m}$ 以下的平原、 阶地、台地占土地面积 $16.54 \%, 100-400 \mathrm{~m}$ 的丘陵占 $54.36 \%, 400-800 \mathrm{~m}$ 的低山占国土面积的 $20.13 \%$, 800-1000m 以上中山占 $3.21 \%$ 。三列东北-西南走向的 山系有: 罗浮山系、莲花山系、凤凰山系; 三列西北- 
东南或近乎南北向的山地有: 七目嶂山地、铁山嶂山 地、蕉平山地，构成梅州的地形格局（图 1）。中部 梅江河及其支流盆谷区, 由梅江河及其支流沿线冲积 盆地和谷地组成; 东南部山高坡陡, 河谷深切, 地形 反差大; 西北低山一丘陵区, 区内陵谷相间, 山势迤通 起伏, 地形高差一般小于 $500 \mathrm{~m}$ 。梅州市地形格局总体 上北东向展布, 以遭受流水切割、搬运和综合外力风 化、剥蚀地质作用为主, 由于雨量充沛, 沟谷密度大, 切割深, 故普遍发育天然的切割面, 这些切割面常以 风化壳底面为侵蚀下限。另一方面, 发育的地表径流不 断冲刷坡脚而塑造不同规模的临空面, 为风化壳滑塌 创造了各种边界条件。地表水沿节理和表层残积物渗 入, 极大地降低了风化层的抗剪强度, 导致滑塌频繁 发生。

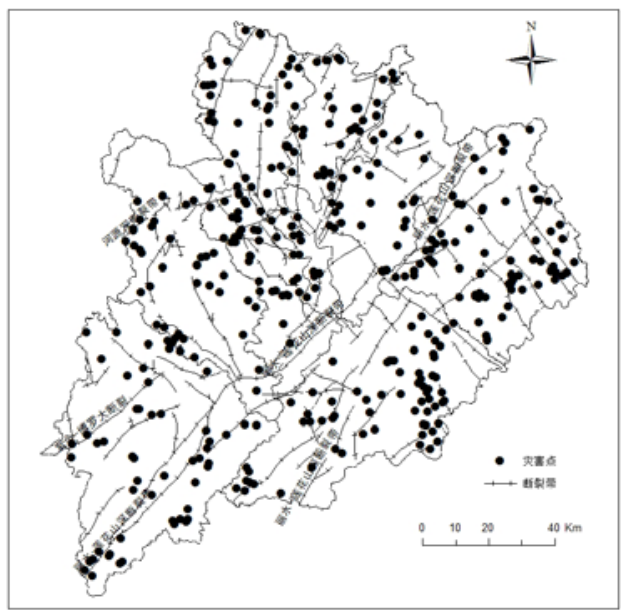

图 2 灾害点与地质构造的关系

\section{3. 华南红壤丘陵区滑坡特性分析 \\ 3.1 时间分布特征}

根据野外调查以及收集当地资料, 本文统计了有 记录的 1058 个滑坡灾害点的发生月份以及当月的雨 量, 滑坡灾害的发生具有明显的季节性, 这种季节性 与降雨的季节性基本吻合。灾害点分布与雨量分布如 图。在全梅州市已知发生时间的地质灾害点中, 有 $92.1 \%$ 处发生在 $4 \sim 8$ 月的雨季。发生于 4 月、 5 月、 6 月、 7 月、 8 月的滑坡数分别占总数的 $10.9 \% 、 23.3 \% 7 、$ $19.6 \% 、 13.8 \% 、 24.5 \%$, 各发生滑坡的百分比与当月降 水量基本成正相关。而干旱季节, 降雨较少，滑坡次 数也相对较少, 仅占滑坡总次数的 $8.9 \%$ 。滑坡一般发 生在暴雨期, 大规模的滑坡暴雨强度临界值为 $200 \mathrm{~mm}$ 以上。

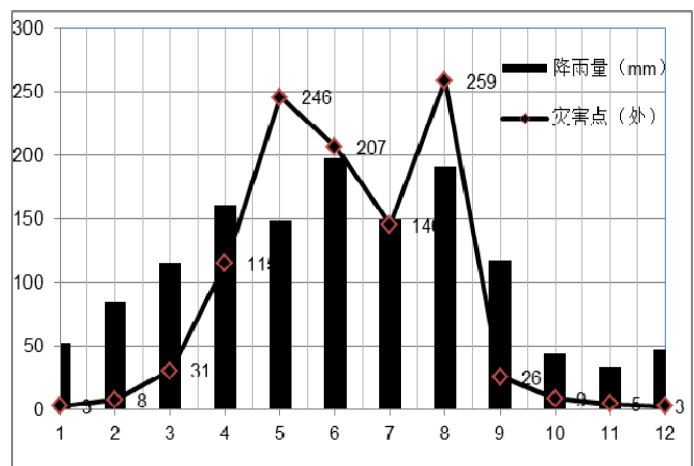

图 3 滑坡灾害点与发生时间及降雨量统计图

\section{2 空间分布特征}

根据区域调查, 目前梅州市共有滑坡 1448 处, 地 质灾害主要分布在丰顺、五华、兴宁、梅县、大埔各 县。

滑坡发育与地形地貌密切相关。从分布空间看，绝大 多数滑坡灾害点分布在海拔 $100 \sim 300 \mathrm{~m}$ 的丘陵地区, 这些区域坡度适宜, 有利于形成较厚的风化壳堆积层。 从坡度分布来看, 最易发生滑坡和崩塌的斜坡坡度为 20- $40^{\circ}$ ，占总地质灾害总数的 $76.8 \%$; 从坡向分布 来看, 阴坡发生地质灾害的概率比阳坡大。

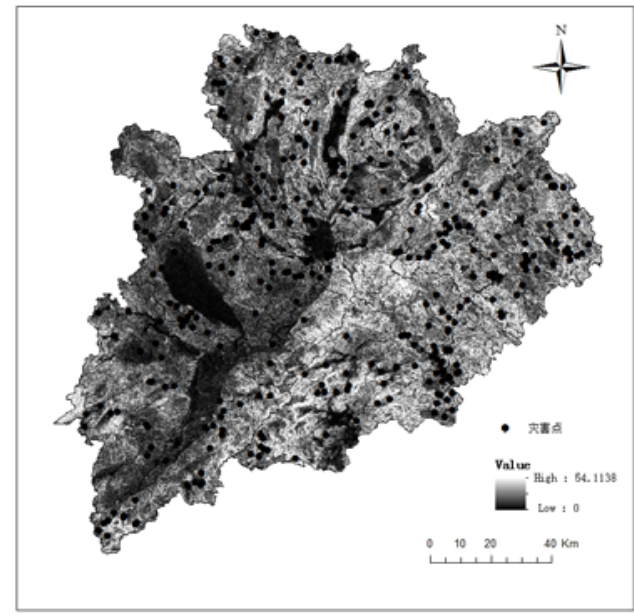

图 4 灾害点与坡度分布图

\section{3 强度特征}

红壤丘陵区的滑坡灾害一般为小型浅层滑坡，滑 体厚度约 $1 \mathrm{~m}$ 左右, 且滑动距离短, 牵引式 (自坡脚逐 级向上牵引发展）, 在山丘陡壁, 陡坡上则常沿裂隙 面发生整体滑塌。据调查, 研究区域内, 灾害体规模属 小型，占 $96.36 \%$; 中型以上占 $3.64 \%$ 。

\section{4. 华南红壤丘陵区滑坡灾害发育影响因素分析}

红壤丘陵区滑坡灾害的形成与发生是多重致灾因 素交互作用的结果, 总体来说, 巨厚的红风化壳和底 部不透水基岩是滑坡灾害发生的物质基础, 其岩性特 征和力学性质是滑坡形成的内在因素, 它在一定程度 上决定着滑坡灾害的发育程度和类型, 地形是地质灾 害形成的外在条件, 它制约着滑坡等致灾作用的形成, 而降水和人类工程活动是地质灾害形成和发育的激发 
因素, 决定着灾害发生的速度和时间。下面从几个方 面探讨红壤区滑坡的生成机理。

\section{1 风化壳的影响}

华南红层风化壳是滑坡形成的物质基础和内在条 件。按照滑坡的物质组成, 对研究区 1448 处滑坡进行 分类统计, 结果表明, 发生在风化壳的土质滑坡有 1392 处, 占滑坡总数的 $96.6 \%$, 而岩质滑坡仅有 56 处，占 $3.4 \%$ 。

从基岩性来看, 滑坡主要发生在与岩浆作用有关、风 化层较厚的块状较硬一坚硬岩组。岩浆岩经强烈的红土 化作用, 脱硅富铁铝、盐基遭受较强烈的淋失, 因而 土体结构疏松, 孔隙较多, 加上风化壳不同层位粒度、 成份、结构等各方面差异, 使得风化壳土体抗冲抗蚀 能力差 ${ }^{[8,}$ 。

除了风化壳本身力学性质差而容易造成滑坡外, 另一个造成滑坡的重要因素是风化壳内部存在大量的 软弱结构面, 它们包括原岩风化后残留下来的构造裂 隙或原生节理, 风化过程中产生的风化节理和卸荷节 理。花岗岩岩体形成时常伴生 3 组以上不同方向的原 生节理。通常在区域构造复杂、褶皱强烈、断层众多、 岩体裂隙发育、新构造引动比较活跃的地区, 往往岩 体破碎、沟谷深切, 较大规模的崩塌、滑坡也比较常 见。梅州市地质构造与滑坡形成和发展的关系表现为 两个方面: 滑坡沿断裂破碎带往往成群成带分布。各 种软弱结构面 (如断层面、岩层面、节理面、片理面 及不整合面等）控制了滑动面的空间展布及滑坡的范 围如图 2。常见的顺层滑坡的滑动面大部分是由岩层 层面或泥化夹层等软弱结构面构成的 ${ }^{[5,7]}$ 。

\section{2 地形的影响}

地形地貌为滑坡灾害的发育提供有利的地形坡度 和临空面, 主要因素有高程、地形坡度和坡向 ${ }^{[8-10]}$ 。

\subsection{1 高程的影响}

地质灾害发育与地形地貌密切相关。高程的变化 对滑坡的影响主要表现在提供高于侵蚀基准面的斜 坡, 使其有可移动的临空面。从分布空间看, 绝大多 数滑坡、崩塌灾害点分布在海拔 $100 \sim 500 \mathrm{~m}$ 的丘陵地 区, 这与丘陵区坡度适宜, 有利于形成较厚的堆积层 有关。结合梅州市 DEM 图, 可得不同高程条件对山地 灾害的敏感性 (表 2)。由表 2, 对山地灾害最敏感的 是 $0-300 \mathrm{~m}$ 高程区域; 最不敏感的为 $>450 \mathrm{~m}$ 的区域。

\begin{tabular}{llllll}
\multicolumn{7}{c}{ 表 2 不同高程条件对滑坡灾害的影响 } \\
\hline 高程 $(\mathrm{m})$ & $<15$ & $150-30$ & $300-45$ & $450-60$ & $>60$ \\
& 0 & 0 & 0 & 0 & 0 \\
\hline 灾害点个数 (个) & 94 & 205 & 68 & 10 & 7 \\
所占比例 $(\%)$ & 24 & 53 & 18 & 3 & 2 \\
\hline
\end{tabular}

\subsection{2 坡度的影响}

崩塌、滑坡的产生、发展及稳定过程, 实质是斜 坡的抗滑力与下滑力失衡过程。对于某一个具体斜坡, 其形态、重度和结构是基本确定的, 在这种情况下, 斜坡的稳定就主要取决于岩土体力学性质, 如 C、 $\phi$ 值大小。( $\mathrm{c}$ 一粘聚力, 是土体颗粒间吸附能力的体现; $\phi$ 一内摩擦角, 是土颗粒间错动能力的体现）。根据 对研究区斜坡体的调查发现, 斜坡坡度受岩土体的物 理力学性质所控制, 特别是岩土体的抗剪强度影响最 显著。在很大程度上，斜坡单元的坡度可以反映岩土 体力学性质。对研究区有坐标信息的灾害点所在的斜 坡单元的平均坡度分级进行统计对比, 结果如表 3 。 从表 3 中可以看出, 最易发生滑坡和崩塌的斜坡坡度 为 $20-40^{\circ}$, 占总地质灾害总数的 $76.8 \%$; 在小于 $15^{\circ}$ 的斜坡上发生滑坡和崩塌较少。在斜坡单元内有坡 度 $>60^{\circ}$ 的人工斜坡, 多数以崩塌为主。

\subsection{3 坡向的影响}

坡向反映了山体斜坡所面对的方向。阳坡（或南 坡) 与阴坡 (或北坡) 之间温度、降水和植被有一定差 异。由于光照、温度、雨量、风速、土壤质地等因子 的综合作用, 坡向能够对斜坡稳定性产生影响。通过 对灾害点与坡向的相关分析表明 (如图 1): 在坡向 0-112. $5^{\circ}$ 共有地质灾害点 212 个, 占所有滑坡点总数 的 $35.15 \%$; 在坡向 $112.5^{\circ}-292.5^{\circ}$ 共有滑坡点 220 个, 占总数的 $36.48 \%$, 在坡向 $292.5^{\circ}-360^{\circ}$ 共有地质灾害 点 171 个, 占总数的 $28.35 \%$ 。可以看出, 在红层风化 壳丘陵区, 阴坡发生地质灾害的概率比阳坡大。

表 3 滑坡个数与斜坡坡度关系

\begin{tabular}{ccccccccc}
\hline $\begin{array}{c}\text { 斜坡度 } \\
\left({ }^{\circ}\right)\end{array}$ & $<15$ & $15-19$ & $20-24$ & $25-29$ & $30-34$ & $35-39$ & $40-45$ & $>45$ \\
\hline $\begin{array}{c}\text { 灾害点 } \\
\text { 数 }\end{array}$ & 7 & 49 & 94 & 132 & 155 & 82 & 56 & 28 \\
$\begin{array}{c}\text { 百分数 } \\
(\%)\end{array}$ & 1.2 & 8.1 & 15.6 & 21.9 & 25.7 & 13.6 & 9.3 & 4.6 \\
\hline
\end{tabular}

\section{3 降水的影响}

红层风化壳的力学性质受水影响显著 []; 由于风 化壳裂隙发育, 遇雨后土体大量吸水饱和使负孔隙水 压消散, 土体增重, 强度显著降低, 导致内摩擦角减 小, 抗剪强度下降, 在重力和地表径流作用下极易发 生土体失稳崩塌、倾覆而形成滑坡。在梅州市已确定 成因的 351 处地质灾害中, 由降雨和人类工程活动因 素共同造成的有 247 处, 占 $75.1 \%$; 由纯降雨因素造 成有 46 处, 占 $14.0 \%$; 由纯人类工程活动因素造成的 有 36 处, 占 $10.9 \%$; 与洪水有关的地质灾害有 22 处, 占 $6.2 \%$ 。这里所指的人类工程主要是指开垦、建房、 修建公路等进行削坡而形成的斜坡。可见，与降雨有 关系的地质灾害占 $89.1 \%$ 。

\section{4 人为活动的影响}

华南红壤丘陵地区的人为活动以农业为主, 主要 以开唇种植和修筑道路居民点, 山坡地开挖而带来的 地形和地下水循环的改变, 进而影响了斜坡稳定性。 本文分析了梅州市土地利用的垦殖指数和建设强度指 数, （厓殖指数指特定区域内已开垦种植的耕地面积 占区域面积的百分比。垦殖指数高, 说明该地区的耕 地开发利用程度较高。建设强度指数指特定区域内已 建设用地面积占总面积的百分比。建设强度指数高, 说明该地区的开发建设程度较高）。结果发现梅州市 滑坡多发生在垦殖指数小于 0.3 的区域, 占地质灾害 总数的 $90 \%$ 以上。这主要是由于垦殖指数小于 0.3 的 
区域主要为大于坡度 $15^{\circ}$ 以上的地区, 这些地区难以 开层作为耕地, 所以其剭殖指数一般较小, 但一旦被 开挖就容易发生崩塌和滑坡等地质灾害。从建设强度 分析看, 滑坡和崩塌等地质灾害多发生在建设强度指 数在 0.05-0.5 的坡地。影响地质灾害形成的工程活动 主要有削坡建房、修建公路、开垦等，尤以削坡建房 为甚。在全市工程活动因素造成的 601 处灾害隐患点 中, 削坡建房造成的有 518 处, 占 $86.12 \%$ ：修建公 路造成的 64 处, 占 $10.64 \%$ 。

\section{5. 结论与讨论}

(1)红壤丘陵区风化壳滑塌是华南沿海地区常见 的一种地质灾害, 由于该区独特的地质环境特点, 使 其规模虽然一般较小, 但其发生频率较高, 常威胁丘 陵山区的农村生产生活。红层风化壳在华南沿海大面 积出露, 其组分和原始的结构构造决定了它的风化壳 具有最大的厚度和最完整的剖面, 红层风化壳构成了 华南丘陵区滑坡灾害的物质基础。

（2）红壤丘陵区的滑坡灾害以小型浅层滑坡为 主, 灾害的发生具有明显的季节性, 这种季节性与降 雨的季节性基本吻合，在空间上，主要分布于 $300 \mathrm{~m}$ 以下的坡度适宜、有较厚的风化层的低山丘陵区。

(3)华南红壤丘陵区滑坡灾害的形成与发生是多 种致灾因素交互作用的结果。红层风化壳的地层岩性 和岩土力学性质是灾害形成的内在要素, 它在一定程 度上决定着地质灾害的发育程度和类型; 地形是灾害 形成的外在条件，它制约着崩、滑、塌等致灾地质作 用的形成; 大气降雨与人类工程活动是地质灾害形成 与发生的激发因素, 决定着灾害发生的速度和时间。

\section{致谢}

本文受国家自然科学青年基金（41201557））、广 东省自然科学基金项目（S2011010004555）、广东省 科学院青年基金项目（qnjj201007）；广东省科技计
划项目（2010A030200020，2011A030200006）资助。

\section{参考文献}

１］吴树仁,田震远, 吴锡浩, 石菊松,雷伟志, 范树应, 胡江, 孙 应举. 四川古萄县蒿枝湾滑坡灾毁土地整理可行性研 究, 水文地质工程地质, (4)2002:21-23.

[2] 张虎男. 华南沿海风化壳滑塌灾害, 海洋地质与第四纪 地质, 15(3) (1995):149-160.

[3] 王清,唐大维,张庆云.中国东部花岗岩残积土物质成分 和结构特征的研究. 长春地质学院学报, 21(1) (1991): 73-81.

４］钟继洪, 唐淑英, 谭军. 南方山区花岗岩风化壳崩岗侵蚀 及其防治对策一一以广东省五华县新一村为例. 水土 保持通报, 11(4) (1991)：25-28.

[5] 吴志峰,王继增. 华南花岗岩风化壳岩土特性与崩岗侵 蚀关系. 水土保持学报, 14 (2) (2000):31-35.

[6] 何珊儒,魏国灵,张福林. 东莞地区花岗岩风化剖面特征 研究. 西部探矿工程，(10）(2005):77-79.

［7］陈明晓. 广东沿海地区花岗岩风化剖面及其差异风化 现象的特征分析.广东公路交通，（1）(2003):59-63.

[8] 陈海滨,陈志彪,陈志强. 红壤侵蚀区花岗岩地质地貌对 水土流失的影响. 亚热带水土保持，22(4)（2010）: $7-9+55$.

［9］丘世钧. 红土坡地崩岗侵蚀过程与机理. 水土保持通报, 14(6) (1994) : 31-40.

[10] 阮伏水, 周伏建. 福建省地貌特征与土壤侵蚀的关系初 探. 水土保持通报, 14(1) (1994):23-29. 